\title{
Barriers to the implementation of mobile phone reminders in pediatric HIV care: a pre-trial analysis of the Cameroonian MORE CARE study
}

Jean Joel R Bigna ${ }^{1,2,3^{*}}$, Jean Jacques N Noubiap ${ }^{4}$, Claudia S Plotte ${ }^{5,6}$, Charles Kouanfack ${ }^{1,7}$ and Sinata Koulla-Shiro ${ }^{1,8}$

\begin{abstract}
Background: Mobile health (mhealth) has emerged as a powerful resource in the medical armamentarium against human immunodeficiency virus (HIV) infection. We sought to determine among adult caregivers of HIV-exposed/ infected children; the extent of mobile phone ownership, the ability to communicate in Cameroon's national official languages (NOL), and the refusal to receive such reminders.

Methods: We conducted a pre-trial analysis of potentials participants of the MORE CARE trial. MORE CARE took place from January through March 2013 in three geographic locations in Cameroon. We included caregivers aged 18 years or older. Written communication was assessed by the ability to read and understand information presented in the consent form. Verbal communication was assessed during a two-way conversation and in a discussion about HIV infection. A question about mobile phone ownership and another about refusal to receive reminders via mobile phone were phrased to allow "Yes" or "No" as the only possible reply. A $p<0.05$ was considered statistically significant.

Results: We enrolled 301 caregivers of HIV-exposed/infected children from rural $(n=119)$, semi-urban $(n=142)$ and urban $(n=40)$ areas of Cameroon. The mean caregiver age was 42.9 years (SD 13.4) and $85 \%$ were women. A fifth of our study population overall had at least one of the three obstacles to mobile phone reminders. By region, 39.5\% in rural, $6.3 \%$ in semi-urban, and $7.5 \%$ in urban setting had at least one obstacle, with significant differences between the rural and urban settings $(p<0.001)$ and the rural and semi-urban settings $(p<0.001)$. The acceptability of SMS was $96.3 \%$ and of mobile phone calls $96 \%$ ( $p=0.054)$. The ability to communicate in NOL orally was $89.7 \%$ and $84.4 \%$ in writing $(p=0.052)$. Mobile phone ownership $(p<0.001 ; p=0.03)$ and the ability to communicate in an NOL orally $(p<0.001$; $p=0.002$ ) or in writing (both $p<0.001$ ), were significantly lower in rural compared to semi-urban and urban settings respectively.
\end{abstract}

Conclusions: The use of mHealth was limited in about one fifth of our population. The greatest obstacle was the inability to use oral or written NOL, followed by non-ownership of a mobile phone. These impediments were higher in a rural setting as compared to urban or semi-urban areas.

Keywords: MORE CARE, Mobile phone, Telecare, Telemedicine, EHealth, Obstacles, mHealth, Literacy, HIV, Caregivers in pediatric HIV

\footnotetext{
* Correspondence: bignarimjj@yahoo.fr

${ }^{1}$ Faculty of Medicine and Biomedical Sciences, University of Yaoundé 1,

Yaoundé, Cameroon

${ }^{2}$ Faculty of Medicine, University of Montpellier 1, Montpellier, France

Full list of author information is available at the end of the article
} 


\section{Background}

The Global Observatory for eHealth defines mobile health (mHealth) as medical and public health practice supported by mobile devices, such as mobile phones, patient monitoring devices, personal digital assistants, and other wireless devices [1]. The United Nations Joint Program on HIV/AIDS (UNAIDS) encourages the use of mHealth in addressing human immunodeficiency virus (HIV) related illnesses and treatments in resource-limited settings [2,3]. According to the International Telecommunications Union, the number of mobile-broadband subscriptions has reached 2.3 billion worldwide in 2014, with $55 \%$ of subscriptions based in developing countries. Africa leads in mobile-broadband growth [4]. MHealth is increasingly recognized as an effective adjunct to HIV control measures [5,6]. Cameroon, a sub-Saharan African country, has seen the proportion of mobile phone users increase rapidly [4,7] as elsewhere in Africa [8], with $60 \%$ of the Cameroonian population owning a mobile phone in 2012 [9]. The use of mobile phones has shown effectiveness in health related behavior change, in screening campaigns, and as a supportive tool in treatment, diagnosis, and data collection [3,6,10-23]. Challenges to the implementation of mHealth include lack of mobile phone ownership and an inability to communicate in national official languages (NOL) both via mobile phone call (oral) and mobile phone text message (SMS) (written). In 2011, about two-third of the adult population in Cameroon were literate [8]. An individual's unwillingness to use a mobile phone for healthrelated communications represents another barrier to acceptance of mHealth. In certain resource-limited settings adherence to mHealth has been shown to be high, despite potential obstacles [6,24-26].

Notwithstanding the proven benefits of the use of mobile phones in the fight against HIV, challenges to implementation remain. Before adopting mobile technologies into the clinical arena, it is imperative to know exactly what e-health architecture to employ within a health system [18]. In Cameroon, the challenges that need to be addressed to effectively and efficiently implement SMS and mobile phone calls in pediatric HIV care remain undefined. In the recently reported MORE CARE (Mobile Reminders for Cameroonian children Requiring HIV treatment) study, we investigated the efficacy and efficiency of mobile phone appointment reminders on the attendance of HIV-exposed or infected children at their previously scheduled follow-up medical appointments [27]. The aim of the present study was to evaluate three factors as potential obstacles to the implementation of using mobile phones (SMS and calls) as medical appointment reminder tools for HIV-exposed and HIV-infected children in Cameroon. More specifically, we sought to investigate the extent of mobile phone non-ownership, the inability to communicate in a NOL, and the refusal to receive mobile phone reminders as variables influencing the acceptance of mobile phones as part of mHealth.

\section{Methods}

\section{Ethical consideration}

The study was approved by the Faculty of Medicine and Biomedical Sciences, University of Yaoundé 1. We obtained ethical clearance from the National Research Ethics Committee for Human Health of Cameroon (Ethical approval $\mathrm{N}^{\circ}$ 2013/03/232/L/CNERSH/SP). All patients included in the study gave their verbal and written consent.

\section{Study design}

This is a pre-trial cross-sectional study of adults included in the MORE CARE trial and addresses mobile phone ownership, an ability to communicate in NOL, and a willingness to receive health-related mobile phone appointment reminders. MORE CARE has been described in detail previously [23,27].

\section{Settings and participants}

Potential participants in the MORE CARE study were enrolled in an urban, a semi-urban, and a rural setting at the Essos National Hospital Insurance Fund, the Kousséri Annex Regional Hospital, and the Goulfey District Hospital respectively [23,27]. Adults aged 18 years or older who accompanied a child to a medical appointment for HIV-related care were invited to enroll in the MORE CARE trial. Only one caregiver present at the time of recruitment was identified for each child. Although that adult caregiver was responsible for ensuring the child's attendance at their next scheduled medical appointment, we did not require that the adult accompanying the child at that follow-up visit be the same adult since MORE CARE was designed to examine each child's presence or absence at their follow-up visit for HIV care.

\section{Appointment reminders in the MORE CARE study}

We briefly report here the MORE CARE mHealth appointment reminder methods, which are further detailed in the published study protocol [27]. The text message sent to caregiver participants was in French or in English (national official languages in Cameroon), and was edited manually. It included the physician's name and the date, time, and location of the appointment. In order to maintain confidentiality and to protect caregiver and patient privacy, the message did not contain information concerning the health status and name of the child, nor the name of the accompanist. The message was sent and each voice phone call placed 48 to 72 hours before the previously scheduled appointment. The content of phone calls was the same as that of the SMS. The communication during phone call was in English or in French, based on the caregiver's stated preference. 


\section{Variables}

We collected the age and sex of caregivers and of the children they accompanied. Obstacles to mHealth appointment reminders investigated were:

1. The non-possession of mobile phone; assessed by asking a potential participant the question, "Do you own a mobile phone?" The answer could only be "Yes" or "No".

2. The inability to understand and read English or French (SMS communication); assessed by the potential participant's inability to read and/or comprehend the informed consent form.

3. The inability to understand and speak English or French (voice phone call communication); assessed by the potential participant's replies to the questions, "What is your name?", "How old are you?", and "Where do you live?", "How did you spend your last holidays?", and the potential participant's ability to have a brief one-on-one discussion about certain aspects of HIV infection.

4. The refusal to receive a SMS or a phone call as follow-up medical appointment reminders; assessed by asking the potential participant directly if he or she wished to receive a reminder via their mobile phone, or not.

\section{Analysis plan}

Data was coded, entered, and analyzed using the Statistical Package for Social Science (SPSS) version 20.0 for Windows (IBM Corp. Released 2011. IBM SPSS Statistics for Windows, Version 20.0. Armonk, NY: IBM Corp.). We described continuous variables using means with standard deviations, and binary variables using their frequencies and percentages. The chi-square test or its equivalents was used to compare binary variables. All statistical tests were performed using two-sided tests at a 0.05 level of significance. We compared the obstacles between study sites, and between communication by SMS and phone call. The Benjamini-Hochberg method was used to adjust the level of significance of comparison between obstacles in each site [28]. WinPepi version 11.25 was used to specifically adjust $p$ values [29].

\section{Results}

We enrolled 301 subjects: 119, 142, and 40 respectively in rural, semi-urban and urban areas. Table 1 shows the general characteristics of the study population. The

Table 1 General characteristics and obstacles to the use of mobile phone reminders for mHealth in Cameroon

\begin{tabular}{|c|c|c|c|c|}
\hline & $\begin{array}{l}\text { Rural } \\
n=119\end{array}$ & $\begin{array}{l}\text { Semi-urban } \\
n=142\end{array}$ & $\begin{array}{l}\text { Urban } \\
n=40\end{array}$ & $\begin{array}{l}\text { Total } \\
\mathrm{N}=301\end{array}$ \\
\hline \multicolumn{5}{|l|}{ General characteristics } \\
\hline \multicolumn{5}{|l|}{ Children } \\
\hline - Mean age, years & $3.6(3.8)$ & $2.6(4.0)$ & $3.0(3.7)$ & $3.1(3.9)$ \\
\hline - Boys & $46(38.7)$ & $70(49.3)$ & $27(67.5)$ & $143(47.5)$ \\
\hline \multicolumn{5}{|l|}{ Caregivers } \\
\hline - Mean age, years & $42.2(12.9)$ & $43.1(13.7)$ & $43.8(13.8)$ & $42.9(13.4)$ \\
\hline - Men & $22(18.5)$ & 19 (13.4) & $5(12.5)$ & $46(15.3)$ \\
\hline \multicolumn{5}{|l|}{ Caregivers level of education } \\
\hline - No formal & $34(28.6)$ & $39(27.5)$ & $8(20.0)$ & $81(26.9)$ \\
\hline - Primary & $55(46.2)$ & $67(47.2)$ & $26(65.0)$ & $148(49.2)$ \\
\hline - Secondary & $16(13.4)$ & $23(16.2)$ & $4(10.0)$ & $43(14.3)$ \\
\hline - University & $14(11.8)$ & $13(9.2)$ & $2(5.0)$ & $29(9.6)$ \\
\hline Time to scheduled appointment, days & $32.1(17.7)$ & $27.7(12.5)$ & $27.8(15.9)$ & $29.5(15.3)$ \\
\hline \multicolumn{5}{|l|}{ Obstacles } \\
\hline At least one obstacle & $47(39.5)$ & $9(6.3)$ & $3(7.5)$ & $59(19.6)$ \\
\hline Without mobile phone & $14(11.8)$ & $1(0.7)$ & 0 & $15(5.0)$ \\
\hline Unable to communicate via text message in NOL & $41(34.5)$ & $5(3.5)$ & $1(2.5)$ & $47(15.6)$ \\
\hline Unable to communicate via voice phone call in NOL & $27(22.7)$ & $4(2.8)$ & 0 & $31(10.3)$ \\
\hline Declined to receive text message & $3(2.5)$ & $5(3.5)$ & $3(7.5)$ & $11(3.7)$ \\
\hline Declined to receive voice phone call & 0 & $2(1.4)$ & $1(2.5)$ & $3(1.0)$ \\
\hline
\end{tabular}


mean age of caregivers was 42.9 years (SD 13.4) and 46 caregivers (15.3\%) were male. Most of them, 148 (49.2\%) had completed a primary level of education.

This study revealed that $80.1 \%$ of the study population did not present any of the obstacles to receiving mobile phone reminders. Regarding each study site, the distribution of the absence of obstacles was: $60.5 \%$ in rural, $93.7 \%$ in semi - urban, and $92.5 \%$ in urban settings. The greatest obstacle was the inability to read an SMS message $(15.6 \%)$ followed by the inability to communicate orally $(10.3 \%)$ in NOL. Very few caregivers refused to receive a SMS $(3.7 \%)$ or a phone call $(1.0 \%)$ to remind them of the child's upcoming medical appointment. The extent of non-possession of a mobile phone was also low (5.0\%) (Table 1).

The occurrence of at least one obstacle to mobile reminders was more frequent in rural than in semi-urban $(p<0.001)$ and urban $(p<0.001)$ areas. Caregivers without a mobile phone were more common in rural than in semi-urban $(p<0.001)$ and urban $(p=0.03)$ areas. The inability to use a NOL for text messaging was more prevalent among caregivers living in a rural area as compared to caregivers living in semi-urban $(p<0.001)$ and urban $(p=0.002)$ areas. There were no differences between geographic areas regarding the refusal to receive text messaging reminder and voice phone call reminders. Also, there was no difference between urban and semiurban areas regarding the mHealth impediments we evaluated (Table 2).

Non-ownership of a mobile phone was associated with geographic areas of residence $(p<0.001)$, and with the inability to use a NOL for text messaging $(p<0.001)$ and voice phone calling $(p<0.001)$ (Table 3$)$. There was no association between caregiver age, sex, level of education attained, or time until the scheduled appointment and the refusal to receive appointment reminder by text message or voice phone call (Table 4). Impediments to using SMS were not significantly different than those to using voice phone calls (Table 5).

Table 2 Comparison of impediments to mobile phone reminders for mHealth between sites ( $p$ values) in Cameroon

\begin{tabular}{llll}
\hline Obstacles & $\begin{array}{l}\text { Urban vs. } \\
\text { semi-urban }\end{array}$ & $\begin{array}{l}\text { Urban } \\
\text { vs. rural }\end{array}$ & $\begin{array}{l}\text { Semi-urban } \\
\text { vs. rural }\end{array}$ \\
\hline At least one obstacle & .73 & $<.001$ & $<.001$ \\
Without mobile phone & 1.0 & .03 & $<.001$ \\
$\begin{array}{l}\text { Unable to communicate via text } \\
\text { message in NOL }\end{array}$ & 1.0 & $<.001$ & $<.001$ \\
$\begin{array}{l}\text { Unable to communicate via voice } \\
\text { phone call in NOL }\end{array}$ & .58 & .002 & $<.001$ \\
$\begin{array}{l}\text { Reject to receive text message } \\
\text { Reject to receive voice phone call }\end{array}$ & .53 & .51 & .73 \\
\hline
\end{tabular}

NOL: National official languages.
Table 3 Comparison of adult caregivers of children requiring follow-up medical care for HIV with and without mobile phone

\begin{tabular}{|c|c|c|c|}
\hline & $\begin{array}{l}\text { With phone } \\
(n=286)\end{array}$ & $\begin{array}{l}\text { Without } \\
\text { mobile phone } \\
(n=15)\end{array}$ & $p$ value \\
\hline \multicolumn{4}{|l|}{ Sites } \\
\hline - Rural & $105(36.7)$ & $14(93.3)$ & $<.001$ \\
\hline - Semi-urban & $141(49.3)$ & $1(6.7)$ & \\
\hline - Urban & $40(14.0)$ & 0 & \\
\hline Caregivers mean age, years & $42.6(13.5)$ & $46.9(11.5)$ & .23 \\
\hline Caregivers male & $43(15.0)$ & $3(20.0)$ & .71 \\
\hline \multicolumn{4}{|l|}{ Caregivers level of education } \\
\hline - No formal/Primary & $219(76.6)$ & $10(66.7)$ & .36 \\
\hline - Secondary/University & $67(23.4)$ & $5(33.3)$ & \\
\hline $\begin{array}{l}\text { Unable to communicate via } \\
\text { text message in NOL }\end{array}$ & $38(13.3)$ & $9(60.0)$ & $<.001$ \\
\hline $\begin{array}{l}\text { Unable to communicate via } \\
\text { voice phone call in NOL }\end{array}$ & $24(8.4)$ & $7(46.7)$ & $<.001$ \\
\hline $\begin{array}{l}\text { Declined to receive } \\
\text { text message }\end{array}$ & $9(3.1)$ & $2(13.3)$ & .09 \\
\hline $\begin{array}{l}\text { Declined to receive } \\
\text { voice phone call }\end{array}$ & $3(1.0)$ & 0 & 1.0 \\
\hline
\end{tabular}

NOL: National official languages.

Data are $\mathrm{n}(\%)$ or mean (standard deviation).

\section{Discussion}

This study reveals that the use of mobile phones for medical follow-up mHealth appointment reminders in pediatric HIV could potentially apply to $80 \%$ of the overall population in Cameroon. Considering each study site separately, the potential penetration of such mHealth use would be different, as we captured $60.5 \%$ of caregivers in rural, $93.7 \%$ of caregivers in semi - urban and $92.5 \%$ of caregivers in urban areas. The greatest obstacle to mobile phone reminders was an adult caregiver's inability to read an SMS message, followed an inability to communicate orally in English or French, which are Cameroon's two national official languages. Very few subjects refused to receive a SMS or a phone call to remind them of the child's medical appointment. The rate of mobile phone non-possession was also low. All impediments to mobile reminders were more frequent in the rural setting, except for the refusal to receive SMS or phone call. SMS or phone call showed no difference in their difficulty of use.

Language illiteracy was the major barrier in our study, as in others [24], and was more pronounced in rural areas in our study. In Uganda, in a region where $80 \%$ of people live in rural areas, most persons speak a local language different than NOL [30]. Before SMS and phone calls can be widely implemented as medical appointment reminders, it will be necessary to assess the feasibility of 
Table 4 Comparison between adult caregivers who rejected or adhered to SMS/voice phone call reminders

\begin{tabular}{|c|c|c|c|c|c|c|c|c|c|}
\hline & \multicolumn{3}{|c|}{ SMS reminder } & \multicolumn{3}{|c|}{ Voice call reminder } & \multicolumn{3}{|c|}{ One of both reminder } \\
\hline & $\begin{array}{l}\text { Adhere } \\
(\mathrm{n}=290)\end{array}$ & $\begin{array}{l}\text { Reject } \\
(n=11)\end{array}$ & $p$ & $\begin{array}{l}\text { Adhere } \\
(\mathrm{n}=298)\end{array}$ & $\begin{array}{l}\text { Reject } \\
(n=3)\end{array}$ & $p$ & $\begin{array}{l}\text { Adhere } \\
(\mathrm{n}=287)\end{array}$ & $\begin{array}{l}\text { Reject } \\
(n=14)\end{array}$ & $\bar{p}$ \\
\hline Caregivers' age, years & $50.0(11.9)$ & $42.6(13.4)$ & .07 & $42.9(13.4)$ & $38.3(11.5)$ & .557 & $47.5(12.4)$ & $42.6(13.4)$ & .18 \\
\hline Male caregivers & $42(14.5)$ & $4(36.4)$ & .07 & $46(15.4)$ & 0 & 1.0 & $42(14.6)$ & $14(100.0)$ & .24 \\
\hline \multicolumn{10}{|l|}{ Caregivers' level of education } \\
\hline - No formal/Primary & $221(76.2)$ & $8(72.7)$ & .73 & $226(75.8)$ & $3(100.0)$ & 1.0 & $218(76.0)$ & $11(78.6)$ & 1.0 \\
\hline - Secondary/University & $69(23.8)$ & $3(27.3)$ & & $72(24.2)$ & 0 & & $69(24.0)$ & $3(21.4)$ & \\
\hline Time to scheduled appointment & $29.4(15.4)$ & $31.8(14.5)$ & .60 & $29.5(15.4)$ & $28.3(3.5)$ & .90 & $29.4(15.4)$ & $31.1(12.9)$ & .69 \\
\hline
\end{tabular}

Data are $\mathrm{n}(\%)$ or mean (standard deviation).

a particular linguistic communication program specific to each health care setting. The literacy rate will need to be improved, especially in rural areas, to help achieve gains in globalization and automation of medical appointment reminders via SMS and phone calls. Health care providers could also adapt and use local languages and dialects to deliver messages about upcoming medical appointments. We suggest that medical assistants in each HIV care center be trained to communicate in the most widely spoken local language (or dialect) in their catchment area in order to reach and include patients and caregivers who communicate exclusively in their local language. The challenge lies in the great number of ethno-linguistic groups in Cameroon, recently assessed at 286 [31]. It will be therefore necessary to target the most widely spoken local languages in each health district.

In our study, $95 \%$ of subjects owned a mobile phone. The rate of ownership is higher than that found in Durban, South Africa in 2010 where 81\% of people living with HIV had a mobile phone [26] and in Nigeria where $68 \%$ of a diabetes population owned a mobile phone [32]. The finding is explained by the exponential increase in the number of subscriptions to mobile phone companies each year $[7,8,24]$. Mobile phone ownership in our 2013 study is however greater than that found in Kenya in the same year (61.2\%) [33]. The difference may reflect the greater proportion of the population living below the national poverty line in Kenya (45.9\% in 2005) as compared to Cameroon (39.9\% in 2007), and by Cameroon's higher per capita Gross National Income as compared to Kenya's [34,35]. In our study, subjects in urban and semi-urban areas owned more mobile phones compared to Kenya's rural areas [33], due to the fact that

Table 5 Comparison of impediments to the use of text message and phone call as appointment reminders

\begin{tabular}{llll}
\hline Obstacles, $\mathbf{n}(\%)$ & Text message & Voice phone call & $\boldsymbol{p}$ value \\
& $\mathbf{n = 3 0 1}$ & $\mathbf{n}=\mathbf{3 0 1}$ & \\
\hline Refusal & $11(3.7)$ & $3(1.0)$ & .054 \\
Unable to communicate & $47(15.6)$ & $31(10.3)$ & .052 \\
\hline
\end{tabular}

the socioeconomic level is lower in rural areas [36]. The observed regional and socioeconomic heterogeneity of mobile phone ownership was also demonstrated in Kenya [37] where factors like gender, educational level, literacy and income are also thought to have an influence on mobile phone ownership [37]. The present study also reveals that people unable to communicate in NOL by text message or orally are most likely not to own a mobile phone. In contrast to another study from sub-Saharan Africa, we found that neither gender nor educational level was a factor in mobile phone ownership [37]. This implies that increasing the NOL literacy rate could lead to an increase in the rate of mobile phone ownership. Although it might be of interest to assess the feasibility and acceptability of using a shared or borrowed mobile phone for appointment reminders and delivery of other healthcare related information for caregivers not owning a mobile phone, we believe that such a "solution" carries significant ethical concerns, especially in regards to privacy and confidentiality.

The acceptability of mobile phones for our mHealth reminder intervention is high (95\%) in our study, as it is in other studies in sub-Saharan Africa [24-26,30,38]. In our study, age, sex, and educational level of the caregivers did not influence acceptability. Also, the interval of time until the scheduled follow-up appointment did not influence acceptability. The adult caregivers were agreeable to receiving an appointment reminder by mobile phone independently of how close or far away the upcoming appointment was in time. The willingness of an adult caregiver to receive mobile phone reminders for a child's follow-up HIV care likely reflects an interest in the well-being and continued optimal care of the child and incorporates the perception that a reminder helps ensure better monitoring and delivery of required ongoing care. It will thus be informative and relevant in future studies to investigate the motivations of caregivers of children exposed to or infected with HIV who refuse to receive mobile phone reminders.

Our study found no significant differences in the rates of refusal between SMS and voice phone calls. Crankshaw 
et al. found a 99\% acceptability for phone calls and 96\% for SMS [26]. Their result is very similar to ours; we achieved $99 \%$ acceptability for calls and $96.3 \%$ for SMS. This suggests that we could freely choose to use SMS or phone calls in sub-Saharan Africa in terms of communication difficulty.

Our study has some limitations. Barriers in addition to those we assessed may impede the use of mobile phones as a medical appointment reminder aid. Examples of obstacles that we did not examine include the timing of sending messages, the unavailability and fluctuations of the wireless network, the phone being powered off, low motivation of medical assistants, and privacy concerns about health $[19,24,26,39]$.

\section{Conclusions}

Despite the proven benefits of mobile health in HIV in sub-Saharan Africa [3,5], the use of mobile phone SMS or voice calls to caregivers providing scheduled appointment reminders for pediatric HIV care in Cameroon encountered a relatively high proportion of obstacles. The most important obstacle was the inability to use spoken or written NOL, followed by non-ownership of a mobile phone. These impediments were higher in a rural area than in urban or semi-urban areas. Rural areas, during the implementation of any health policy based on SMS and phone calls, would thus benefit from a targeted program addressing difficulties in communicating in verbal and written NOL and low mobile phone ownership rate. In terms of acceptability and efficiency, both SMS and phone calls were equivalent when used as mHealth reminder tools in our Cameroonian population of adult caregivers of children requiring HIV care.

\section{Abbreviations \\ HIV: Human immunodeficiency virus; MHealth: Mobile health; NOL: National official languages; SMS: Text message (short message service).}

\section{Competing interests}

The authors declare that they have no competing interest.

\section{Authors' contributions}

JJRB conceived and designed the study, collected, analyzed and interpreted data, and drafted the manuscript. JJNN designed the study and drafted the manuscript. CK, and SKS designed the study and critically reviewed the manuscript. CSP critically reviewed, revised, and edited, the manuscript. All authors approved the final version to publish.

\section{Author's information}

JJRB (MD) conducted this study in the course of earning his inter-university diploma in the management of HIV infection from the University of Yaoundé 1 , Cameroon and the University of Montpellier 1, France. CK is a faculty member in the training program and SKS is the coordinator of the training program.

\section{Acknowledgments}

We acknowledge all MORE CARE participants. Funding: This study received no external funding and was completely financed by personal funds of corresponding author (JJRB).

\section{Author details}

${ }^{1}$ Faculty of Medicine and Biomedical Sciences, University of Yaoundé 1, Yaoundé, Cameroon. ${ }^{2}$ Faculty of Medicine, University of Montpellier 1 , Montpellier, France. ${ }^{3}$ Preventing Mother to Child Transmission Unit, Goulfey District Hospital, Goulfey, Cameroon. ${ }^{4}$ Internal Medicine Unit, Edéa Regional Hospital, Edéa, Cameroon. ${ }^{5}$ Department of Medicine, New York University Langone Medical Center, New York, USA. ${ }^{6}$ Department of Medicine, Division of Translational Medicine, New York University School of Medicine, New York, USA. ${ }^{7}$ Accredited Treatment Centre, Yaoundé Central Hospital, Yaoundé, Cameroon.

${ }^{8}$ Infectious Disease Unit, Yaoundé Central Hospital, Yaoundé, Cameroon.

Received: 1 February 2014 Accepted: 13 October 2014

Published online: 26 October 2014

\section{References}

1. World Health Organization: mHealth: New horizons for health through mobile technologies: second global survey on eHealth. In http://www. who.int/goe/publications/goe_mhealth_web.pdf.

2. UNAIDS: Resource needs for an expanded response to AIDS in low- and middle-income countries. In http://data.unaids.org/pub/Report/2005/ jc1255_resource_needs_en.pdf.

3. UNAIDS: Telecom: tools connecting the world and communicating about HIV. In http://www.unaids.org/en/KnowledgeCentre/Resources/Feature Stories/archive/2009/20091005_telecom.asp.

4. International Telecommunications Union: ICT: facts and figures. In http://www. itu.int/en/TU-D/Statistics/Documents/facts/CTFactsFigures2014-e.pdf.

5. UNAIDS: Preventing HIV with social media and mobile phones. In http://www.unaids.org/en/resources/presscentre/featurestories/2011/may/ $20110502 \mathrm{sm} /$.

6. Thirumurthy $H$, Lester RT: M-health for health behaviour change in resource-limited settings: applications to HIV care and beyond. Bull World Health Organ 2012, 90(5):390-392.

7. Nana ON, Tankeu RK: Cameroon. In Towards an African e-Index: Household and Individual ICT Access and Usage across 10 African Countries. Edited by Gillwald A. 2005:46-65.

8. Cellular-news: African continent fastest mobile growth market. In http://www.cellular-news.com/story/15908.php.

9. Wolrd Health Organization: Cameroon statistics summary (2002 - present): country profile. In http://apps.who.int/gho/data/node.country.country-CMR.

10. Horvath T, Azman H, Kennedy GE, Rutherford GW: Mobile phone text messaging for promoting adherence to antiretroviral therapy in patients with HIV infection. Cochrane Database Syst Rev 2012, 3:CD009756.

11. Kunutsor S, Walley J, Katabira E, Muchuro S, Balidawa H, Namagala E, Ikoona E: Using mobile phones to improve clinic attendance amongst antiretroviral treatment cohort in rural Uganda: a cross-sectional and prospective study. AIDS Behav 2010.

12. Car J, Gurol-Urganci I, de Jongh T, Vodopivec-Jamsek V, Atun R: Mobile phone messaging reminders for attendance at healthcare appointments. Cochrane Database Syst Rev 2012, 7:CD007458.

13. UNAIDS: Cambodia's HIV Hotline - advice and counselling just a phone call away. In http://www.unaids.org/en/resources/presscentre/featurestories/ 2006/september/20060927cambodia/.

14. Seidenberg P, Nicholson S, Schaefer M, Semrau K, Bweupe M, Masese N, Bonawitz R, Chitembo L, Goggin C, Thea DM: Early infant diagnosis of HIV infection in Zambia through mobile phone texting of blood test results. Bull World Health Organ 2012, 90(5):348-356.

15. Hasvold PE, Wootton R: Use of telephone and SMS reminders to improve attendance at hospital appointments: a systematic review. J Telemed Telecare 2011, 17(7):358-364.

16. Jian WS, Hsu MH, Sukati H, Syed-Abdul S, Scholl J, Dube N, Hsu CK, Wu TJ, Lin V, Chi T, Chang P, Li YC: LabPush: a pilot study of providing remote clinics with laboratory results via short message service (SMS) in Swaziland, Africa. PLoS One 2012, 7(9):e44462.

17. de Jongh T, Gurol-Urganci I, Vodopivec-Jamsek V, Car J, Atun R: Mobile phone messaging for facilitating self-management of long-term illnesses. Cochrane Database Syst Rev 2012, 12:CD007459.

18. Piette JD, Lun KC, Moura LA Jr, Fraser HS, Mechael PN, Powell J, Khoja SR: Impacts of e-health on the outcomes of care in low- and middle-income countries: where do we go from here? Bull World Health Organ 2012, 90(5):365-372.

19. Lester RT, Ritvo P, Mills EJ, Kariri A, Karanja S, Chung MH, Jack W, Habyarimana J, Sadatsafavi M, Najafzadeh M, Marra CA, Estambale B, Ngugi E, Ball TB, Thabane L, 

message service on antiretroviral treatment adherence in Kenya (WelTel Kenya1): a randomised trial. Lancet 2010, 376(9755):1838-1845.

20. Pop-Eleches C, Thirumurthy H, Habyarimana JP, Zivin JG, Goldstein MP, de Walque D, MacKeen L, Haberer J, Kimaiyo S, Sidle J, Ngare D, Bangsberg DR: Mobile phone technologies improve adherence to antiretroviral treatment in a resource-limited setting: a randomized controlled trial of text message reminders. AIDS 2011, 25(6):825-834.

21. Mukund Bahadur KC, Murray PJ: Cell phone short messaging service (SMS) for HIV/AIDS in South Africa: a literature review. Stud Health Technol Inform 2010, 160(Pt 1):530-534.

22. Mbuagbaw L: Mobile phone reminders for paediatric HIV follow-up care. Lancet Infect Dis 2014, 14(7):540-541.

23. Bigna JJ, Noubiap JJ, Kouanfack C, Plottel CS, Koulla-Shiro S: Effect of mobile phone reminders on follow-up medical care of children exposed to or infected with HIV in Cameroon (MORE CARE): a multicentre, single-blind, factorial, randomised controlled trial. Lancet Infect Dis 2014, 14(7):600-608.

24. Déglise $C$, Suggs $L S$, Odermatt P: Short message service (SMS) applications for disease prevention in developing countries. J Med Internet Res 2012, 14(1):e3.

25. Deglise C, Suggs LS, Odermatt P: SMS for disease control in developing countries: a systematic review of mobile health applications. J Telemed Telecare 2012, 18(5):273-281.

26. Crankshaw T, Corless IB, Giddy J, Nicholas PK, Eichbaum Q, Butler LM: Exploring the patterns of use and the feasibility of using cellular phones for clinic appointment reminders and adherence messages in an antiretroviral treatment clinic, Durban, South Africa. AIDS Patient Care STDS 2010, 24(11):729-734.

27. Bigna JJ, Kouanfack C, Noubiap JJ, Plottel CS, Koulla-Shiro S: A randomized blinded controlled trial of mobile phone reminders on the follow-up medical care of HIV-exposed and HIV-infected children in Cameroon: study protocol (MORE CARE). Trials 2013, 13(1):313.

28. Benjamini Y, Hochberg Y: Controlling the false discovery rate: a practical and powerful approach to multiple testing. J Roy Stat Soc Ser B 1995, 57:289-300.

29. Abramson JH: WINPEPI updated: computer programs for epidemiologists, and their teaching potential. Epidemiol Perspect Innovat 2011, 8:1.

30. Siedner MJ, Haberer JE, Bwana MB, Ware NC, Bangsberg DR: High acceptability for cell phone text messages to improve communication of laboratory results with HIV-infected patients in rural Uganda: a crosssectional survey study. BMC Med Inform Decis Mak 2012, 12:56.

31. Ethnologue: Languages of the World. In http://wnw.ethnologue.com/Country/CM.

32. Okoro EO, Sholagberu HO, Kolo PM: Mobile phone ownership among Nigerians with diabetes. Afr Health Sci 2010, 10(2):183-186.

33. Zurovac D, Otieno G, Kigen S, Mbithi AM, Muturi A, Snow RW, Nyandigisi A: Ownership and use of mobile phones among health workers, caregivers of sick children and adult patients in Kenya: cross-sectional national survey. Global Health 2013, 9:20.

34. The World Bank Group: Kenya Data. In http://data.worldbank.org/country/kenya.

35. The World Bank Group: Cameroon Data. In http://data.worldbank.org/ country/cameroon

36. Central Technical Group of National AIDS Control Commitee of Cameroon: Rapport national de suivi de la déclaration politique sur le VIH/SIDA. In http//:www.unaids.org/en/dataanalysis/knowyourresponse/country progressreports/2012countries/ce_CM_Narrative_Report.pdf.

37. Wesolowski A, Eagle N, Noor AM, Snow RW, Buckee CO: Heterogeneous mobile phone ownership and usage patterns in Kenya. PLoS One 2012, 7(4):e35319.

38. van Heerden A, Norris S, Tollman S, Richter L, Rotheram-Borus MJ: Collecting maternal health information from HIV-positive pregnant women using mobile phone-assisted face-to-face interviews in Southern Africa. J Med Internet Res 2013, 15(6):e116.

39. Siedner MJ, Lankowski A, Musinga D, Jackson J, Muzoora C, Hunt PW, Martin JN, Bangsberg DR, Haberer JE: Optimizing network connectivity for mobile health technologies in sub-Saharan Africa. PLoS One 2012, 7(9):e45643.

doi:10.1186/s12913-014-0523-3

Cite this article as: Bigna et al:: Barriers to the implementation of mobile phone reminders in pediatric HIV care: a pre-trial analysis of the Cameroonian MORE CARE study. BMC Health Services Research 2014 14:523.

\section{Submit your next manuscript to BioMed Central and take full advantage of:}

- Convenient online submission

- Thorough peer review

- No space constraints or color figure charges

- Immediate publication on acceptance

- Inclusion in PubMed, CAS, Scopus and Google Scholar

- Research which is freely available for redistribution 